\title{
Scenario Simulation of the Industrial Sector Carbon Dioxide Emission Reduction Effect
}

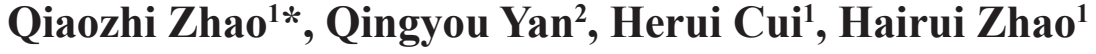 \\ ${ }^{1}$ North China Electric Power University, 619 North Yong-hua Street, Baoding, China \\ ${ }^{2}$ North China Electric Power University, 2 Bei-nong Road, Beijing, China
}

Received: 24 April 2017

Accepted: 4 June 2017

\begin{abstract}
Differentiated carbon dioxide emission reduction targets and optimizing industrial incentive policy is an important subject in China's low-carbon economic transformation. With the application of the environmental input-output (EIO) method and the bi-proportional scaling updating schedule, the inter-industrial inputoutput tables in 2017 are forecasted and then carbon dioxide emissions of 30 industrial sectors are simulated in seven scenarios. Based on these results, conclusions are:

1. Twenty-five high carbon dioxide emission sectors among 30 national sectors are divided into three types. Five sectors are whole-process high carbon dioxide emission type, 18 are conductive type, and two are apparent high type.

2. Final demands keep the dominant role in pushing sectorial emissions growing, whether in total carbon dioxide emission intensity or emission quantities. Technical progress leads to emissions declines in intensity and quantity. Moreover, special energy-saving technical progress will gradually exceed universal technical progress in reduction effects. Whole-process high carbon sectors are the best selection to gain favorable incentive policies to promote carbon dioxide emissions reduction. Apparent high carbon sectors are in last place.

3. With incentive policies being improved, technical progress reduction effect is increasing. However, it is not enough to offset the driving effect from final demands growing in seven scenarios. More favorable incentives and investments should be allocated into high emission sectors, especially into the most sensitive ones.
\end{abstract}

Keywords: carbon dioxide emission reduction effect, environmental input-output method, technical progress

\section{Introduction}

China has made great efforts to promote its low-carbon transformation process and realize its reduction targets of 2020 and 2030. Since the 11th five-year period, carbon

*e-mail: zhaoqiaozhi2006@126.com emission reduction has been an important constraint in economic and social development. "Action Plan 201220 for Addressing Climate Change of Industrial Sectors," "Light Industrial Sector Development Plan 2016-20," and "National Agricultural Sustainable Development Planning 2016-30" have been the central arrangements for Chinese industrial sectors in recent years. The Chinese economy has entered into a "new-normal" stage in which 
medium-high growth and economic structure adjustments are the significant characters. This raises many risks while also supplying opportunities for carbon emission reduction. In the 13th five-year period, technical progress and economic structure are given more focus than before. Therefore, how to optimize incentive policies among sectors is one core subject to stimulate emission reduction effects. Complex production correlations and energy consumption intensity differences among industrial sectors should be considered when policies are implemented. In this study, the environmental input-output model is used to consider these characters among all sectors in China. After estimating carbon dioxide emission effects in different scenarios, varied sector emission reduction suggestions are brought out to optimize reduction incentive policies.

Abundant literature has been published in recent years regarding China's carbon dioxide emission reduction policies. Most research concerns national economic emission reduction analysis and regional or sectorial emission reduction fields. Concerning the regional emission reduction fields, many conclusions have been made. Zhu J. [1], Qu Chao [2], Lu C., and Zhang X. [3] have studied the carbon dioxide emissions situation in Hebei Province, 30 other provinces, the western region, and Shaanxi Province, respectively, and supplied detailed reduction suggestions. In terms of sectorial emission reduction, Li Hong studied the industrial sector's emission situation and found its scale and technical degree have inhibitory effects on its emission intensity in China [4]. Ren YS analyzed the carbon dioxide emissions of nine industrial sectors in Guangdong and made reduction effects analysis in different scenarios [5]. Lin Bo-qiang analyzed the reduction characteristics in the Chinese non-metallic mineral products and transport sectors [6-8]. Gao Biao estimated the agricultural sector's carbon dioxide emission reduction potentials of Bai-cheng in China [9]. Wu QL applied the LEAP-power model to estimate the carbon dioxide reductions of the electric power sector in China in six scenarios up to 2030 [10]. Concerning the industrial sector's emission reduction analysis, conclusions are mainly focused upon one sector or minor sectors' reduction policies, and they paid little attention to the links in carbon dioxide emissions among sectors. Complex sectorial associations in production process and different emission intensity make sectorial links important in exploring optimal measures in China. When the goods of one industrial sector are produced, fossil energies are consumed and emissions are brought out. This kind of emission is defined as direct carbon. When the goods from another sector are input to this sector production, emissions are flowed to this sector correspondingly. Carbon dioxide flows among industrial sectors should be considered in exploring the optimal path to promote low-carbon transformation. Yang SS analyzed the sectors' associations in emissions in secondary industries and evaluated the reduction effects based on the input-output model [11]. Thus, this study analyzes the carbon dioxide emission flows among all industrial sectors and simulates sectorial reduction scenarios.
Literature on the impacts of technological progress on carbon dioxide emissions mainly focuses on total reduction effect evaluation. Qiao estimated the technological progress's influences on industrial sector emissions [12]. $\mathrm{Xu}$ Y.Z. analyzed the short- and long-term effects of environmental regulation policies on carbon emissions in China [13]. Wang Z.L. indicated the carbon reduction effects of eight industrial sectors in Beijing based on the grey relevancy method [14]. Zheng researched emission reduction of technological progress in China [15]. Johnston analyzed emission reduction effects of technology advances in Britain [16]. Many models have been developed to indicate emission reduction effects. Wu [11] and Chang [17] tried to analyze emission reduction effects in many scenarios based on LEAP model. Liu Xiaomin, Liu, and Xu used the CGE model to estimate emission reductions in China [18-20]. Decomposition analysis methods are utilized to evaluate technological impact on carbon emissions [21-25]. Association among sectors in carbon emissions is not considered comprehensively through the above-noted methods. The input-output method was developed by Leontief in 1936 and widely used to analyze sectors' production associations. Miller and Blair developed the input-output method for energy and environmental analysis [26]. Many researchers have used this method in energy and emissions analysis [27-32]. The environmentally extended input-output model has been used for final use-based environmental accounting [33]. Thus, this paper intends to indicate the reduction effects of 30 sectors through the input-output method in the $13^{\text {th }}$ five-year period of China $\left(13^{\text {th }}-\mathrm{FYPiCh}\right)$.

The contributions of this paper may be summarized as follows: considering the carbon flows among 30 sectors in China, the indirect and total carbon dioxide emissions are measured through sectorial input-output model. Furthermore, it is also used to simulate the various scenarios for reduction potential of China under different technological progress and economic development scenarios. The results can evaluate the future trend of China's carbon dioxide emissions, as well as provide some general insights to the countermeasures aimed at energysaving and emission-reduction, which is beneficial for policy-making and realizing the 2020 and 2030 reduction targets.

\section{Material and Methods}

\section{Environmental Input-Output Model}

The input-output model is an analytical framework for analyzing production associations among industrial sectors in an economy. Now this model has been extended to many other fields, such as interregional flows of goods and services, energy flows, and environmental pollution associations with their activities. The environmental input-output model is applied to account for inter-sectorial associations in environmental analysis. In this study, the EIO model is constructed among all sectors in China to 
measure carbon emission characters. Direct carbon dioxide emission intensity of sector $j$ is defined as evaluating carbon emissions quantity per output. It is represented as $D C I_{j}$ and $n$ sectors form $D C I$ row vector. $D C I_{j}$ is calculated as follows in Eq. (1):

$$
D C I_{j}=\frac{\sum_{j} E_{j k} \cdot \lambda_{k}}{x_{j}}
$$

... where $E_{j k}$ is the direct consumption caused by fuel $k$ in sector $j ; \mathrm{k}=1,2, \mathrm{~L}, 8$ is the fuel type; and $\lambda_{k}$ is the emission coefficient of fuel $k$ (IPCC 2006).

$T C I$ is also a row vector of total carbon dioxide emission intensity per final output. It contains its direct and indirect emissions. Indirect emissions happen accompanied with production input among sectors. Based on the input-output model, TCI is represented as Eq. (2) and total carbon emissions are obtained as in Eq. (3):

$T C I=D C I+D C I \times A+D C I \times A^{2}+\ldots+D C I \times A^{n}+\ldots=D C I \times(I-A)^{-1}$

$$
T C_{j}=T C I_{j} \times Y_{j}
$$

In Eq. (2), $I$ is the identity matrix, $A$ is the direct input coefficient matrix among sectors, and $(I-A)^{-1}$ are defined as Leontief inverse matrix to represent total input coefficients among sectors. The input-output table issued by the China Statistical Bureau is of competitive type and the imported goods are shown in the final demand. Intermediate input goods include two parts: domestic and imported goods. Thus, imported goods should be excluded from input coefficient matrix $A$. Otherwise, $T C I$ will be seriously overestimated. Based on the handling method of the Chinese Input-Output Association [34], a diagonal matrix $\hat{m}$ is formed to estimate ratios of imported goods in proportion to total goods. In sector $i$, imported demands proportion $m_{i}$ can be calculated using Eq. (4):

$$
m_{i}=\frac{I m_{i}}{I m_{i}+x_{i}}
$$

$A$ is adjusted to as in Eq. (5) and, correspondingly, TCI is repeated to calculate.

$$
A^{\prime}=(I-\hat{m}) \cdot A
$$

\section{Input-output Data Updating Method}

The EIO model is used to analyze carbon dioxide emission reduction effects of sectors on the premise of input-output table forecast in the $13^{\text {th }}-\mathrm{FYPiCh}$. Hence, the forthcoming input-output table is of 2017, to be released by the China Statistical Bureau in approximately 2020. Many researchers have devoted their efforts to updating inputoutput table information on some reasonable assumptions. Gao Minxue and Xu Jian have used the bio-proportional scaling method $(R A S)$ to update the input-output tables and conclude that it has good statistical properties [26]. The main steps are:

1. Assumptions and primary forecast. First, prices remain unchanged from 2012 to 2017. Then final goods and added values data in the second and third quadrants are forecast. It is assumed that total outputs, final outputs, and values added of sectors keep the same speed during 2012-17 as during 2007-12. Under the two assumptions, total outputs, final outputs, and values added of 30 sectors in 2017 are forecast and represented by vectors $X^{\iota}, Y^{\iota}$, and $V^{\iota}$.

2. Row adjustment. The input coefficient matrix in 2012 and 2017 is represented by $A^{0}$ and $A^{\sim}$, respectively. $\hat{X}^{\sim}$ is a diagonal matrix transformed from $X^{\smile}$ and $I F=A^{0} \times \hat{X}^{\iota}$. If $I F=I F^{r}=X^{\iota}-Y^{\iota}$, this means that no change happens and no row adjustment is needed. Otherwise, $A^{0}$ should be revised. Revised matrix $\hat{R}(1)$ is shown in Eq. (6). Revised flow matrix in first quadrant is $X^{I F}=\hat{R}(1) A_{0} \times \hat{X}^{-}$.

3. Column adjustment. Based on $X^{I F}$ in the above, column sum vector $M I$ is calculated by the sum of each column in $X^{I F}$. Intermediate input column vector $M I^{S}$ in 2017 is $X^{\swarrow}-V^{\longleftarrow}$. Thus the column-revised matrix $\hat{S}(1)$ is calculated as in Eq. (6) and $X^{I F}=\hat{R}(1) A_{0} \times \hat{X}^{\complement} \times \hat{S}(1)$.

$$
\begin{aligned}
\hat{R}(1) & =\left[\begin{array}{cccc}
r_{1}^{1} & 0 & \cdots & 0 \\
0 & r_{2}^{1} & \cdots & 0 \\
\vdots & \vdots & \ddots & \vdots \\
0 & 0 & \cdots & r_{n}^{1}
\end{array}\right], r_{i}^{1}=\frac{I F_{i}^{r}}{I F_{i}} \\
\hat{S}(1) & =\left[\begin{array}{cccc}
s_{1}^{1} & 0 & \cdots & 0 \\
0 & s_{2}^{1} & \cdots & 0 \\
\vdots & \vdots & \ddots & \vdots \\
0 & 0 & \cdots & s_{n}^{1}
\end{array}\right], s_{i}^{1}=\frac{M I_{i}^{s}}{M I_{i}}
\end{aligned}
$$

3. Similarly, after iterations $m$ times, the revised coefficients tend to converge, and when errors ratios are kept within acceptable ranges, iterations end. Final revised row matrix $\hat{R}$ and column matrix $\hat{S}$ are obtained as in Eq. (7), and final input coefficient matrix is as in Eq. (8):

$$
\begin{aligned}
& \hat{R}=R(m) \times R(m-1) \cdots R(1) ; \hat{S}=S(m) \times S(m-1) \cdots S(1) \\
& \breve{A}=\hat{R} \times A_{0} \times \hat{S}
\end{aligned}
$$

\section{Carbon Reduction Scenarios Design}

From the previous literature, factors affecting carbon dioxide emissions mainly include economic growth rate, industrial structure, energy consumption intensity, and type structure. According to Eq. (2), the faster the economic growth rate, the faster total carbon emissions grow under the assumption that total carbon dioxide emission intensity is constant. That is, economic growth promotes increasing 
emissions. On the other hand, carbon dioxide emission reduction should own to a decrease of total emission intensity. The more the total emission intensity decreases, the greater the emission reduction effects. Based on Eqs. (1-3), energy consumption intensity, energy type structure, and sectors demand structure influence total carbon dioxide emission intensity. In input-output analysis framework, Leontief inverse matrix $(I-A)^{-1}$ represents inter-sector associations in production process, and its change reflects overall technical progress. In this study, $(I-A)^{-1}$ is used to represent universal technical change in China. Based on Eq. (1), the change of energy consumption intensity and energy type structure can be reflected by direct emission intensity vector. Decrease of $D C I$ indicates the special technical progress in energy-saving fields, and we define its special energy-saving technical progress. An indicator that influences total carbon dioxide emissions of a sector is its final demand. Out of respect for all sectors, final demands growth influences total emissions among sectors. Above all, total carbon emission changes result from three factors: universal technical progress, special energy-saving technical progress, and final demands change. Scenarios in the $13^{\text {th }}-\mathrm{FYPiCh}$ are designed from these three aspects.

In China, technical innovation is gaining more and more attention in society. Especially in the $13^{\text {th }}-\mathrm{FYPiCh}$, green development has been one of the five development concepts in central government. The $13^{\text {th }}$-FYPiCh National Science and Technology Innovation Planning announced in 2016 gives detailed information on technical progress. Now, the government will give more favorable supporting policies to promote technical progress in sectors. On conditions of input-output table updating as noted earlier, final demand growth and universal technical progress are represented through $Y$ and $A$ in the five-year period. As a result, scenarios are conducted with DCI changes (see in Table 3). Three types of scenarios are as follows: NTES, CTES, and NTES. NTES is a scenario in which no special technical progress happens in all sectors; CTES is one with consistent special technical progress among all sectors, and DTES is considered differentiated special technical progress in $13^{\text {th }}$-FYPiCh (Table 1). In CTES, three sub-scenarios are categorized according to DCI decrease ratios: T10\%, T20\%, and T30\%. In NTES, all sectors are categorized into four types: low-carbon sectors,

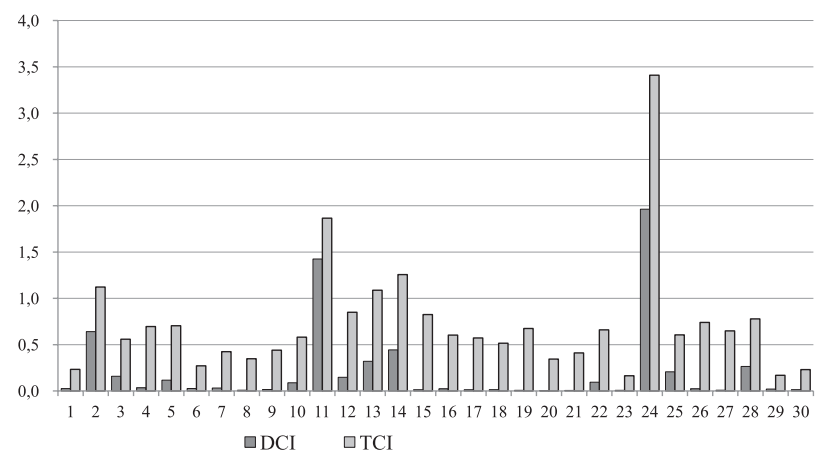

Fig. 1. Carbon dioxide emission intensities of 30 sectors in 2012 (unit: tons per $10^{4}$ yuan). whole-process high-carbon sectors, conductive highcarbon sectors, and apparent high-carbon sectors. Subscenarios in NTES are conducted when the three highcarbon sectors are given more favorable incentive policies and direct carbon intensity decreases by $30 \%$. In total, seven scenarios are considered in this study as follows in Table 1. In each scenario, $\Delta C_{t}$ is carbon dioxide emission change vector of all sectors. It is decomposed into three parts: $\Delta C_{Y}, \Delta C_{A}$, and $\Delta C_{P}$, which represent final demand effects, universal technical progress effect, and special energy-saving technical progress effect, respectively. The calculations are as follows in Eq. (11).

$$
\begin{aligned}
& \Delta C_{Y}=T C I^{\prime} \cdot\left(Y^{\prime}-Y^{0}\right) ; \\
& \Delta C A=\left(T C I^{\prime}-T C I^{0}\right) \cdot Y_{0} ; \\
& \Delta C_{I}=\Delta C_{t}-\Delta C_{Y}-\Delta C_{A}
\end{aligned}
$$

\section{Results and Discussion}

\section{Carbon Dioxide Emission Situations of 30 Sectors in China}

The main economic data are from China input-output table 2012 and it reflects current sectorial economic and technical level information [35]. Energy consumption information is from the China Energy Statistical Yearbook 2013 [36]. Forty-two sectors are merged into 30 sectors in accordance with sector classifications in industrial energy consumption information (Table 1). The carbon dioxide emission coefficients of each fuel type are based on 2006 guidelines from the Intergovernmental Panel on Climate Change (IPCC 2006). Total carbon dioxide emissions of 30 sectors are also estimated with Eqs. (1-3). In 2012 total emissions of 30 sectors were 3,042 million tons. In direct emissions, the three highest-contributing sectors are electric power production and supply, petroleum processing and coking, and ferrous and nonferrous metal processing. From the aspect of total carbon dioxide emissions, the most contributory sectors are construction, other services, and transportation equipment.

With Eqs. (1-2), DCI and TCI are calculated (Fig. 1) in 30 sectors. Their intensities varied in direct and total intensities. Compared with direct and total emission intensity, sectors are categorized into four types: low carbon type, whole-process high type, conductive high type, and apparent high type. If a sector has higher direct and total intensities, it is defined as a whole process type. A sector with lower direct intensity and higher total intensity is categorized into conductive high type. Conductive high sectors are characterized as lots of carbon dioxide emissions flowing into these types, accompanied with goods from other sectors. If it is higher direct intensity and lower total intensity, it is of apparent type. The apparent high sectors may be a source of carbon dioxide emission flows. And if two intensities of a sector are both lower, it is low carbon type. From Fig. 1, five sectors (1, 6, 23, 29, 
Table 1. Sector classification in EIO analysis.

\begin{tabular}{|c|c|c|c|}
\hline No. & Sector category & No. & Sector category \\
\hline 1 & Agriculture & 16 & General equipment manufacturing \\
\hline 2 & Coal mining and dressing & 17 & Special equipment manufacturing \\
\hline 3 & Petroleum and natural gas extraction & 18 & Transportation equipment \\
\hline 4 & Ferrous, nonferrous mining and dressing & 19 & Electrical equipment and machinery \\
\hline 5 & nonmetal and other mining and dressing & 20 & Electric, communication equipment \\
\hline 6 & Food production, tobacco processing & 21 & Instrument equipment \\
\hline 7 & Textile & 22 & Other manufacturing \\
\hline 8 & Garments and related products & 23 & Waste disposals \\
\hline 9 & Timber processing and furniture & 24 & Electric power production and supply \\
\hline 10 & Printing, cultural and sports articles & 25 & Gas production and supply \\
\hline 11 & Petroleum processing and coking & 26 & Water production and supply \\
\hline 12 & Chemical materials and products & 27 & Construction \\
\hline 13 & nonmetal mineral products & 28 & Transport, storage, postal services \\
\hline 14 & Ferrous, nonferrous metals processing & 29 & Wholesale, retails, hotels, and catering \\
\hline 15 & Metal products & 30 & other service activities \\
\hline
\end{tabular}

and 30) are low carbon type; such sectors as 2, 11, 13, 14, and 24 are whole-process high type; two sectors ( 3 and 25 ) are apparent high type; and the other 18 sectors are divided into conductive high type. Different kinds of sectors may have different reduction effects and need differentiated incentive policies.

\section{Input-Output Data in 2017 Updating Results}

According to the RAS updating schedule noted earlier, iterations are conducted. In each iteration relative error sum squares of 30 sectors are calculated. When iterations rise, errors decrease. After eight iterations, errors tend to

Table 2. Coefficients of 30 sectors in updating IO tables.

\begin{tabular}{|c|c|c|c|c|c|}
\hline Sector No. & $\hat{R}_{i i}$ & $\hat{S}_{i i}$ & Sector No. & $\hat{R}_{i i}$ & $\hat{S}_{i i}$ \\
\hline 1 & 0.9489 & 0.9591 & 16 & 0.6834 & 1.0889 \\
\hline 2 & 1.7661 & 0.7134 & 17 & 1.1451 & 1.0252 \\
\hline 3 & 1.1351 & 0.9500 & 18 & 0.5641 & 1.1869 \\
\hline 4 & 1.1547 & 0.8671 & 19 & 0.9920 & 0.9990 \\
\hline 5 & 0.9021 & 0.8477 & 20 & 0.9401 & 0.9914 \\
\hline 6 & 1.1262 & 0.9719 & 21 & 0.9070 & 1.0317 \\
\hline 7 & 0.9869 & 1.0047 & 22 & 0.2660 & 1.0220 \\
\hline 8 & 0.6645 & 1.0415 & 23 & 0.6625 & 1.1687 \\
\hline 9 & 0.9861 & 1.0102 & 24 & 0.9365 & 0.8604 \\
\hline 10 & 0.7642 & 1.0576 & 25 & 0.7232 & 0.8600 \\
\hline 11 & 0.9599 & 0.8567 & 26 & 1.5666 & 0.9414 \\
\hline 12 & 1.0130 & 0.9664 & 27 & 1.0116 & 0.8775 \\
\hline 13 & 1.0560 & 0.9626 & 28 & 1.1716 & 1.0790 \\
\hline 14 & 0.9821 & 0.9742 & 1.0064 & 30 & 0.5776 \\
\hline 15 & 0.9764 & & & 0.8921 \\
\hline
\end{tabular}


Table 3. Scenarios and their descriptions.

\begin{tabular}{|c|c|c|}
\hline \multicolumn{2}{|c|}{ Scenarios } & Descriptions \\
\hline NTES & $\mathrm{T} 0 \%$ & $\begin{array}{l}\text { Carbon emissions are driven by universal technical progress and final demands growth; no special } \\
\text { technical progress in energy-saving fields happens in } 30 \text { sectors. }\end{array}$ \\
\hline \multirow{3}{*}{ CTES } & $\mathrm{T} 10 \%$ & $\begin{array}{l}\text { Carbon emissions are driven by universal technical progress and final demands growth; special } \\
\text { technical progress in energy-saving fields makes DCI decrease by } 10 \% \text { in } 30 \text { sectors. }\end{array}$ \\
\hline & T20\% & $\begin{array}{l}\text { Carbon emissions are driven by universal technical progress and final demands growth; special } \\
\text { technical progress in energy-saving fields makes DCI decrease by } 20 \% \text { in } 30 \text { sectors. }\end{array}$ \\
\hline & $\mathrm{T} 30 \%$ & $\begin{array}{l}\text { Carbon emissions are driven by universal technical progress and final demands growth; special } \\
\text { technical progress in energy-saving fields makes DCI decrease by } 30 \% \text { in } 30 \text { sectors. }\end{array}$ \\
\hline \multirow{3}{*}{ DTES } & WH30\% & $\begin{array}{l}\text { Carbon emissions are driven by universal technical progress and final demands growth; special } \\
\text { technical progress only makes whole-process high sectors direct carbon intensity decrease by } 30 \% \text {. }\end{array}$ \\
\hline & $\mathrm{CH} 30 \%$ & $\begin{array}{l}\text { Carbon emissions are driven by universal technical progress and final demands growth; special } \\
\text { technical progress only makes conductive high sectors direct carbon intensity decrease by } 30 \% \text {. }\end{array}$ \\
\hline & АН $30 \%$ & $\begin{array}{l}\text { Carbon emissions are driven by universal technical progress and final demands growth; special } \\
\text { technical progress only makes apparent high sectors direct carbon intensity decrease by } 30 \% \text {. }\end{array}$ \\
\hline
\end{tabular}

be stable and iterations end. In the end, total error ratio is $4.36 \%$. The final adjusting coefficients of 30 sectors are listed in Table 2.

\section{Total Carbon Intensity Reduction Effects of All Scenarios}

Based on Eqs. (1-6) and RAS results, the total carbon dioxide emission intensity in 2017 of all scenarios can be estimated. Table 4 is the TCI results in seven scenarios. The total emission intensity decreased with DCI decreases from $0 \%$ to $30 \%$ in the first four scenarios. Scenario T0\% is the TCI results when DCI in 2017 remains the same as in 2012. Scenarios T10\%, T20\%, and T30\% are simulation results of TCI when DCI decreases by $10 \%, 20 \%$, and $30 \%$ in comparison with DCI in 2012. The last three scenarios are trying to consider the TCI changes when special energy-saving technical progress happens in the three types of high carbon sectors, respectively. WH30\% in Table 4 is the TCI in 2017 if only the five whole-process

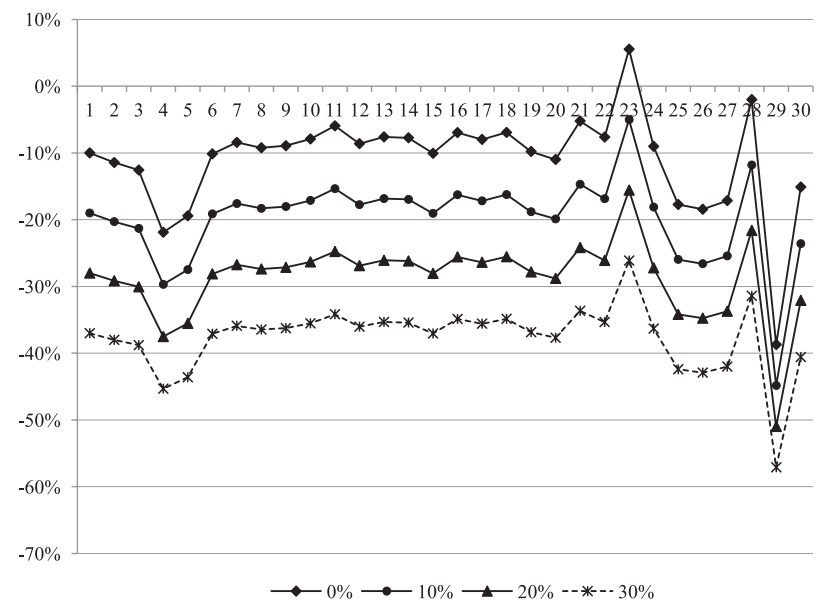

Fig. 2. TCI change ratios of 30 sectors in NTES and CTES (unit: \%). high-type sectors enjoy favorable incentive policies to reduce their emission technology among 30 sectors and, correspondingly, their direct emission intensity is reduced by $30 \%$. CH30\% is the TCI in 2017 when 18 conductive sectors reduced direct intensity by $30 \%$. AH $30 \%$ is the TCI in 2017 when two apparent high-carbon sectors reduce direct emission intensity by $30 \%$. TCI in $\mathrm{WH} 30 \%$, $\mathrm{CH} 30 \%$, and $\mathrm{AH} 30 \%$ varies differently among 30 sectors. The three scenarios are being considered as reduction effects when few sectors are given favorable incentive policies for resources, and investments are limited and they should be allocated reasonably. T30\% is the TCI reduction effect when all sectors enjoy indiscriminative incentive policies among 30 sectors. A comparison is trying to evaluate three high-carbon type sectors with T30\%.

The change ratio of TCI in the first four scenarios is shown in Fig. 2. TCI of all sectors decreases with DCI reduction more and more, except sector 23 in the T0\% scenario. Moreover, total carbon dioxide emission intensities of 30 sectors decrease at different ratios. In T0\%, universal technical progress and final demands

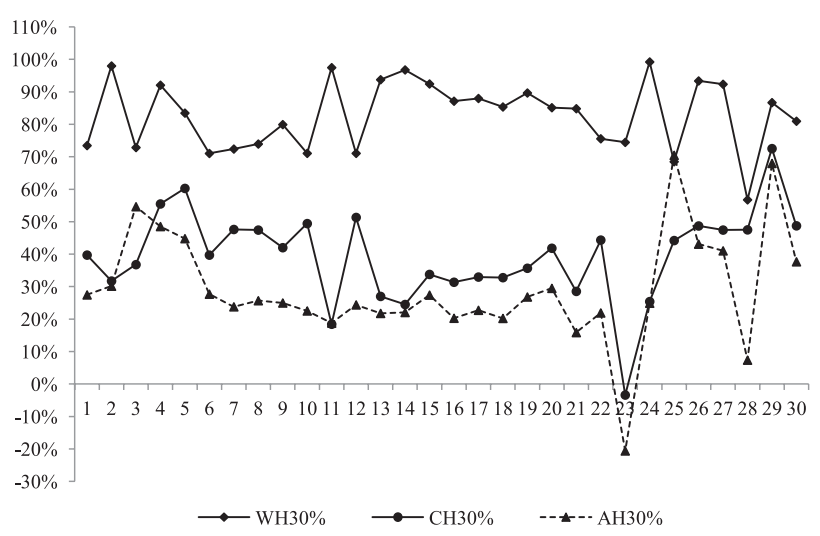

Fig. 3. TCI change ratios of three scenarios in DTES, compared with T30\% scenarios (unit: \%). 
Table 4. Total carbon dioxide emission intensity in seven scenarios (unit: tons per $10^{4}$ yuan).

\begin{tabular}{|c|c|c|c|c|c|c|c|}
\hline Sectors & $\mathrm{T} 0 \%$ & $\mathrm{~T} 10 \%$ & $\mathrm{~T} 20 \%$ & Т $30 \%$ & WH30\% & СH30\% & АH $30 \%$ \\
\hline 1 & 0.2336 & 0.1892 & 0.1682 & 0.1472 & 0.1701 & 0.1992 & 0.2098 \\
\hline 2 & 1.1221 & 0.8944 & 0.7950 & 0.6956 & 0.7042 & 0.9868 & 0.9935 \\
\hline 3 & 0.5590 & 0.4399 & 0.3910 & 0.3422 & 0.4010 & 0.4793 & 0.4405 \\
\hline 4 & 0.6950 & 0.4886 & 0.4343 & 0.3800 & 0.4050 & 0.5202 & 0.5421 \\
\hline 5 & 0.7043 & 0.5107 & 0.4540 & 0.3972 & 0.4480 & 0.5192 & 0.5667 \\
\hline 6 & 0.2719 & 0.2199 & 0.1955 & 0.1710 & 0.2002 & 0.2318 & 0.2440 \\
\hline 7 & 0.4248 & 0.3501 & 0.3112 & 0.2723 & 0.3144 & 0.3522 & 0.3885 \\
\hline 8 & 0.3483 & 0.2845 & 0.2529 & 0.2213 & 0.2544 & 0.2880 & 0.3157 \\
\hline 9 & 0.4406 & 0.3611 & 0.3210 & 0.2809 & 0.3129 & 0.3735 & 0.4007 \\
\hline 10 & 0.5814 & 0.4819 & 0.4284 & 0.3748 & 0.4346 & 0.4793 & 0.5349 \\
\hline 11 & 1.8664 & 1.5798 & 1.4043 & 1.2287 & 1.2448 & 1.7489 & 1.7466 \\
\hline 12 & 0.8496 & 0.6988 & 0.6211 & 0.5435 & 0.6321 & 0.6925 & 0.7749 \\
\hline 13 & 1.0880 & 0.9048 & 0.8042 & 0.7037 & 0.7277 & 0.9843 & 1.0044 \\
\hline 14 & 1.2569 & 1.0437 & 0.9277 & 0.8118 & 0.8261 & 1.1478 & 1.1588 \\
\hline 15 & 0.8245 & 0.6674 & 0.5932 & 0.5191 & 0.5421 & 0.7213 & 0.7408 \\
\hline 16 & 0.6035 & 0.5053 & 0.4492 & 0.3930 & 0.4201 & 0.5375 & 0.5608 \\
\hline 17 & 0.5723 & 0.4739 & 0.4213 & 0.3686 & 0.3931 & 0.5051 & 0.5260 \\
\hline 18 & 0.5157 & 0.4319 & 0.3840 & 0.3360 & 0.3623 & 0.4568 & 0.4794 \\
\hline 19 & 0.6746 & 0.5477 & 0.4868 & 0.4260 & 0.4517 & 0.5859 & 0.6079 \\
\hline 20 & 0.3447 & 0.2761 & 0.2454 & 0.2148 & 0.2341 & 0.2903 & 0.3064 \\
\hline 21 & 0.4106 & 0.3503 & 0.3114 & 0.2724 & 0.2934 & 0.3712 & 0.3887 \\
\hline 22 & 0.6601 & 0.5488 & 0.4878 & 0.4268 & 0.4838 & 0.5566 & 0.6090 \\
\hline 23 & 0.1638 & 0.1556 & 0.1383 & 0.1210 & 0.1320 & 0.1653 & 0.1727 \\
\hline 24 & 3.4094 & 2.7917 & 2.4815 & 2.1713 & 2.1808 & 3.0948 & 3.1010 \\
\hline 25 & 0.6058 & 0.4486 & 0.3987 & 0.3489 & 0.4298 & 0.4922 & 0.4247 \\
\hline 26 & 0.7402 & 0.5434 & 0.4830 & 0.4226 & 0.4436 & 0.5855 & 0.6033 \\
\hline 27 & 0.6489 & 0.4839 & 0.4301 & 0.3763 & 0.3972 & 0.5196 & 0.5370 \\
\hline 28 & 0.7787 & 0.6868 & 0.6104 & 0.5341 & 0.6399 & 0.6625 & 0.7607 \\
\hline 29 & 0.1689 & 0.0932 & 0.0828 & 0.0725 & 0.0853 & 0.0990 & 0.1034 \\
\hline 30 & 0.2303 & 0.1760 & 0.1564 & 0.1369 & 0.1546 & 0.1848 & 0.1951 \\
\hline
\end{tabular}

commonly drive carbon dioxide emission changes. In the $\mathrm{T} 10 \%, 20 \%$, and $30 \%$ scenarios, special energy-saving, universal technical progress and final demands together lead to sectorial emissions changes. In all four scenarios, TCI of 30 sectors varied at different ratios. Such sectors as 23 and 28 decrease at the lowest velocity in total emission intensity. Except for Garment and the related products and waste disposal sectors, 28 sectors decrease significantly.

When discriminated incentive policies are implemented in three high-emission-type sectors, respectively, each type sector gained differentiated TCI reduction effects.
Compared with TCI reduction effect in the T30\% scenario (Fig. 3), TCI reduction effect in the $\mathrm{WH} 30 \%$ scenario is most satisfactory among the three. Scenario $\mathrm{CH} 30 \%$ is in the second order in reduction effects and $\mathrm{AH} 30 \%$ scenario is the least. Whole-process high-emissiontype sectors include five sectors: 2, 11, 13, 14, and 24 . Conductive high-emission-type sectors include 18 sectors and apparent high-type includes two sectors. Thus the whole-process high-emission-type sectors are the most economical and should be in the first place to be given incentive policies. 
Table 5. Carbon dioxide emission changes and decomposition results in sub-scenarios.

\begin{tabular}{|c|c|c|c|c|c|c|c|}
\hline \multirow{2}{*}{\multicolumn{2}{|c|}{ Scenarios }} & \multicolumn{2}{|c|}{$\Delta C_{A}$} & \multicolumn{2}{|c|}{$\Delta C_{I}$} & \multicolumn{2}{|c|}{$\Delta C_{Y}$} \\
\hline & & \multirow{2}{*}{$\begin{array}{c}\text { Quantity } \\
\left(10^{4} \text { tons }\right) \\
-373\end{array}$} & \multirow{2}{*}{$\begin{array}{c}\text { Ratios } \\
(\%)\end{array}$} & \multirow{2}{*}{$\begin{array}{c}\text { Quantity } \\
\left(10^{4} \text { tons }\right)\end{array}$} & \multirow{2}{*}{$\begin{array}{c}\text { Ratios } \\
(\%)\end{array}$} & \multirow{2}{*}{$\begin{array}{c}\begin{array}{c}\text { Quantity } \\
\text { (10 tons) }\end{array} \\
2667\end{array}$} & \multirow{2}{*}{$\begin{array}{c}\begin{array}{c}\text { Ratios } \\
(\%)\end{array} \\
87.65\end{array}$} \\
\hline NTES & T0\% & & & & & & \\
\hline \multirow{3}{*}{ CTES } & $\mathrm{T} 10 \%$ & -373 & -12.24 & -267 & -8.78 & 2400 & 78.88 \\
\hline & T20\% & -373 & -12.24 & -534 & -17.55 & 2133 & 70.12 \\
\hline & T30\% & -373 & -12.24 & -801 & -26.33 & 1867 & 61.35 \\
\hline \multirow{3}{*}{ DTES } & WH30\% & -373 & -12.24 & -630 & -20.71 & 2043 & 67.15 \\
\hline & СH30\% & -373 & -12.24 & -132 & -4.33 & 2536 & 83.35 \\
\hline & АH $30 \%$ & -373 & -12.24 & -5.34 & -0.18 & 2658 & 87.38 \\
\hline
\end{tabular}

\section{Total Carbon Dioxide Emission Reduction Effects of All Scenarios}

With Eq. (3), total carbon dioxide emissions changes can be estimated, and absolute changes of 30 sectors are obtained in scenarios. As shown in Fig. 4, T30\% has the least emissions rise aggregately. Compared with emissions in 2012, the first four scenarios have increased by $75.41 \%, 57.87 \%, 40.33 \%$, and $22.79 \%$. Under indifferent incentive policies among 30 sectors, emission growth ratio decreases $17.54 \%$ from $\mathrm{T} 10 \%$ to $\mathrm{T} 30 \%$. Compared with emissions change in $\mathrm{T} 30 \%$, if only five wholeprocess high type sectors were given favorable incentives, carbon dioxide emissions will increase by $50 \%$. Similarly, 18 conductive high-carbon sectors will lead to 1.93 times, and two apparent high carbon sectors will bring out 2.29 times growth. In view of absolute changes, the WH30\% scenario should be the most satisfying schedule among the last three scenarios.

Based on Eq. (12), total carbon dioxide emission changes are decomposed into three effects (as shown in Table 5 and Fig. 5). In Fig. 5, universal technical progress leads to a decrease of 373 million tons, with approximately a $12.24 \%$ decrease. Special energy-saving technical progress leads to $8.78 \%, 17.55 \%$, and $26.33 \%$ declines in

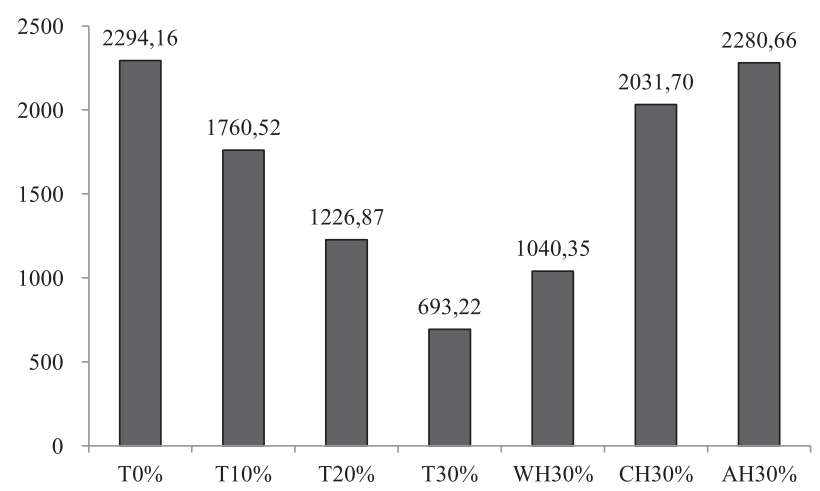

Fig. 4. Total carbon emission changes in seven scenarios (unit: $10^{6}$ tons)
T10\%, T20\%, and T30\% scenarios. When DCI decreases exceed $10 \%$, special technical progress effects are more than those resulting from universal technical progress in 2017. Final demand growth makes a declining positive emission effect in four scenarios. In the T30\% scenario, final demand growth leads to a $61.35 \%$ increase of total carbon dioxide emissions compared with emissions in 2012. Final demand growth is always the main factor driving carbon dioxide emissions rises in the future. However, special energy-saving technical progress shall play a more important role in reducing emissions than universal technical progress. Based on decomposition results of the last three scenarios, they are compared with $\mathrm{T} 30 \%$ effects. In view of total effects, the WH30\% scenario has the least and $\mathrm{AH} 30 \%$ has the most effects. As shown in Fig. 6, the $\mathrm{WH} 30 \%$ scenario has the least driving effect and the most mitigating effect. It is also the best sector to gain favorable incentive policies to stimulate carbon dioxide emissions reductions. Conductive highcarbon sectors should be the second place with their relative lower demand effect and fewer reduction effects of the three scenarios.

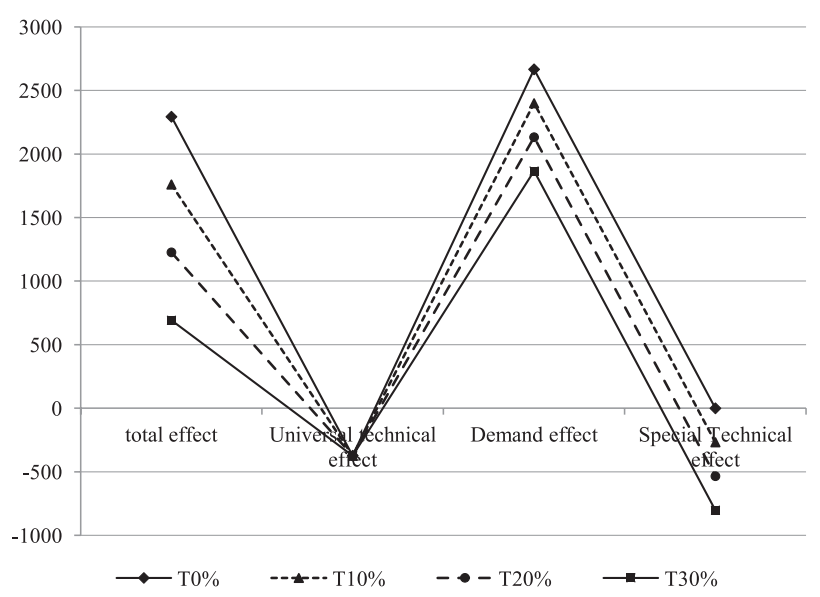

Fig. 5. Total effects and factor effects in NTES and CTES (unit: \%). 


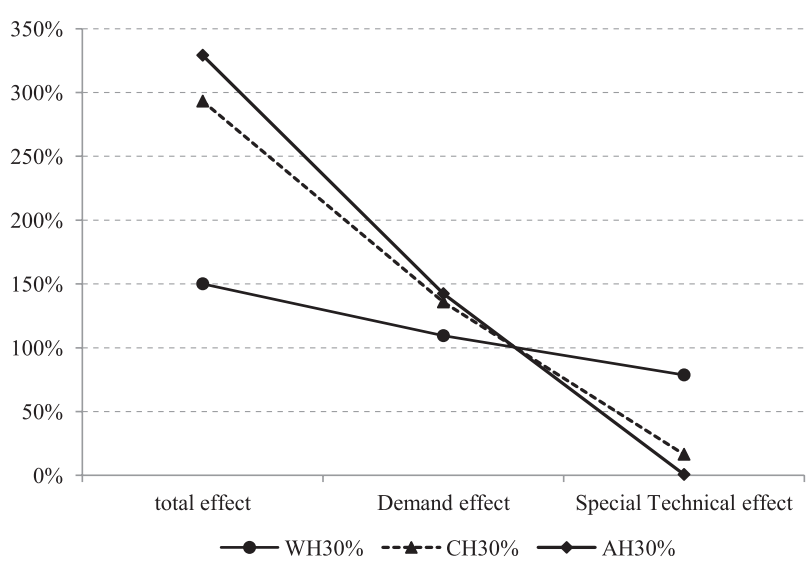

Fig. 6. Effects ratios of sub-scenarios of DTES compared with effects of T30\% (unit: \%).

\section{Conclusions}

Based on the environmental input-output model and RAS updating method, carbon dioxide emissions situations of 30 sectors are evaluated and their reduction effects are estimated in 2017 of $13^{\text {th }}-\mathrm{FYPiCh}$ in seven scenarios. Our main conclusions follow.

Firstly, it will be a long time before China realizes its low-carbon economic transformation. Final demands of sectors play a dominant role in pushing rising emissions. Sectorial demand structure optimization has an important effect on carbon economy formation. The economy in China grows at the speed of $6 \sim 7 \%$ and residual living standards are growing quickly at the present stage. Final demands should grow at high speed for the long term. Maybe demand structure optimization, which guides residual consumption for low emission products, will polish up these emission growth effects. More green products and services are supplied to consumers accompanied by growing residual living standards, which will promote the process of low-carbon economic transformation in China. Compared with the reduction effects in seven scenarios, technological progress is the core factor for promoting declining emissions, whether in carbon dioxide emission intensity or in carbon emission quantity. In the short term, universal technical progress cuts down emissions through production associations among sectors, and in the 13thFYPiCh it brings out fewer effects than special energysaving technical progress. In the $13^{\text {th }}$-FYPiCh, supplyside structural reform is carried out in depth. High energy consumption and high emission sectors are facing serious transition pressures, such as the iron and steel industry, power generation sectors, etc.

Secondly, technical progress is the key factor for promoting low-carbon dioxide emission formation. For high emission sectors, how to push forward energysaving technical progress is an important subject. On one hand, R\&D funds in energy-saving and emission reduction fields should be invested more during the 13thFYPiCh. Compared with these effects, whole-process high emission sectors are the most satisfactory types of the three. Thus, when carbon dioxide emissions targets in China are decomposed into all sectors, whole-process type sectors should undertake the most reduction commitments, whether in reducing total carbon intensity or total carbon emissions. Technological progress has the most potential to cut emissions. Especially technological advances in energy-saving and emission reduction fields shall be the first order to push emissions reduction. On the other hand, scientific and technical achievements transformation and emission reduction technology introduction are also important influential factors.

\section{Acknowledgements}

This study was supported by the China Central Universities Funds Project (grant No. 9160613012).

\section{References}

1. ZHU J., LIU XM. Accounting and reduction policy on carbon emissions from energy activities. China Population, Resources and Environment, 26 (7), 70, 2016.

2. QU C., CHEN T. Estimation to China's $\mathrm{CO}_{2}$ emissions intensity in 2030: based on IPAT model of FA. China Population, Resources and Environment, 26 (7), 62, 2016.

3. GAO X.C., MA L. The carbon emission effect and reduction potential estimation from the open economy in Western regions of China. Journal of Southwest University for Nationalities (Humanities and Social Science edition), (1), $112,2015$.

4. LU C., ZHANG X., HE J. A CGE analysis to study the impacts of energy investment on economic growth and carbon dioxide emission: A case of Shaanxi Province in western China. Energy, 35 (11), 4319, 2010.

5. REN S.Y., WANG P., ZHAO D.Q., DAI H.C. Research on carbon emissions cap and emission reduction path of key industries in Guangdong province based on CGE model. Ecological Economy, 32 (7), 69, 2016.

6. LIN B.Q., OUYANG X.L. Analysis of energy-related $\mathrm{CO}_{2}$ emissions and reduction potential in the Chinese non-metallic mineral products industry. Energy, 68, 688, 2014.

7. XU BIN, LIN B.Q. Carbon dioxide emissions reduction in China's transport sector: A dynamic VAR approach. Energy, 83, 486, 2015.

8. LIN B.Q., LEI X.J. Carbon emissions reduction in China's food industry. Energy Policy, 86, 483, 2015.

9. GAO B., FANG J., XU Q.T., LI Y.B., LU X.L. Dynamic change and analysis of reduction potential of agricultural carbon emissions in Bai-cheng City. Journal of Chinese Agricultural Mechanization, 37 (9), 195, 2016.

10. WU Q.L., PENG C.Y. Scenario analysis of carbon emissions of China's electric power industry up to 2030. Energies, 9, 988, 2016.

11. YANG S.S. Evaluation and prediction on carbon emissions transferring across the industrial sectors in China. China Industrial Economics, 327 (6), 55, 2015.

12. QIAO Z., CAO L.Z. The $\mathrm{CO}_{2}$ emission reduction effect of technological progress in industry: an empirical analysis based on Chinese industrial data during 2001-2010. The Northern Forum, 256 (2), 155, 2016. 
13. XU Y.Z., YANG Y.C. The effects and path of environmental regulation on Chinese carbon emissions. Soft Science, 4, 63, 2015.

14. WANG Z.L., WEI J. An analysis on the effect of the carbon emission reduction of industrial technological progress. Ecological Economy, 31 (4), 64, 2015.

15. ZHENG Y.F., LI H.T., WU R.J., WANG L.X. Impact of technology advances on China's $\mathrm{CO}_{2}$ emission reduction. Chinese Science Bulletin, 55, 1983, 2010.

16. JOHNSTON D., LOWE R., BELL M. An exploration of the technical feasibility of achieving $\mathrm{CO}_{2}$ emission reductions in excess of $80 \%$ within the UK housing stock by the year 2050. Energy Policy, 33, 1643, 2005.

17. CHANG Z., PAN K.X. An analysis of Shanghai's long-term energy consumption and carbon emission based on LEAP Model. Contemporary Finance \& Economics, 350 (1), 98, 2014.

18. LIU X.M., FU J.F. Analysis of the scenarios of China's carbon intensity reduction in 2020 based on the CGE model. Resources Science, 33 (4), 634, 2011.

19. LIU YU, HU X.H. Economic and Environmental implications of raising China's emission standard for thermal power plants: an environmentally extended CGE model-based analysis. Climate Change Research, 12 (2), 154, 2016.

20. XU S.C., ZHANG W.W. Analysis of impacts of carbon taxes on China's economy and emissions reduction under different refunds: based on dynamic CGE model. China Population, Resources and Environment, 26 (12), 46, 2016.

21. SUN Z.R., ZHOU D.Q., ZHOU P. Driving forces of industrial $\mathrm{CO}_{2}$ emissions: a new production-based decomposition analysis method. The Journal of Quantitative \& Technical Economics, 5, 63, 2012.

22. ZHAO Y.H., LI H., ZHANG Z., ZHANG Y.F., WANG S., LIU Y. Decomposition and scenario analysis of $\mathrm{CO}_{2}$ emissions in China's power industry: based on LMDI method. Natural Hazards, 86 (3), 645, 2017.

23. SHAO S., ZHANG X., ZHAO X.R. Empirical decomposition and peaking pathway of carbon dioxide emissions of China's manufacturing sector: generalized divisia index method and dynamic scenario analysis. China Industrial Economics, 3, 44, 2017.
24. SHAHIDUZZAMAN M., LAYTON A. Decomposition analysis for assessing the United States 2025 emissions target: how big is the challenge?. Renewable \& Sustainable Energy Reviews, 67, 372, 2016.

25. RONALD E., MILLER P.D. Blair, Input-Output Analysis Foundations and Extensions, $2^{\text {nd }}$ ed.; Cambridge University Press: Cambridge, UK, 446, 2009 [In UK].

26. SHENG Z.L., WANG X.Y., XIN Y.F., HAO R. Study and estimation of embodied carbon based on input-output analysis. Journal of Scientific \& Industrial Research, 75, 529, 2016.

27. ZHANG Q., NAKATANI J., MORIGUCHI Y. Compilation of an embodied $\mathrm{CO}_{2}$ emission inventory for China using 135-sector input-output tables. Sustainability, 7, 8223, 2015.

28. CHEN W.D., WU F.Y., GENG W.X., YU G.Y. Carbon emissions in China's industrial sectors. Resources, Conservation and Recycling, 117, 264, 2017.

29. QI S.C., WANG F., ZHANG Y.X. China's non-competition input-output table and its application. Statistical Research, 25 (8), 79, 2008.

30. FAN DAN Driving factors of carbon emissions from energy consumption in China - Based on LMDI-PDA method. China Environmental Science, 33 (9), 1705, 2013.

31. JIANG JINHE Analysis of key drivers on China's carbon emissions and policy rethinking based on LMDI: 1995-2010. Journal of Resources and Ecology, 4 (4), 304, 2013.

32. JANIS BRIZGA, KUISHUANG FENG, KLAUS HUBACEK. Household carbon footprints in the Baltic States: a global multi-regional input-output analysis from 1995 to 2011. Applied Energy, 189, 780, 2017.

33. Researching group of Chinese input-output association. Input-output analysis of water resources consumption and water input coefficient in national economic sectors: the fifth of researching report series on input-output tables of 2002. Statistical Research, 24 (3), 20, 2007.

34. Department of national economic accounting, National Bureau of Statistics. Input Output Tables of China. China Statistical Press: Beijing, China, 2015 [In China].

35. Department of Energy statistics, National Bureau of Statistics. China Energy Statistical Yearbook. China Statistical Press: Beijing, China, 2014 [In China]. 